\title{
A tentative analysis of the causal stress factors of graduate students of the University of New Mexico in Albuquerque, New Mexico
}

\author{
Yolanda E. Ledesma iD, Ángel R. Cobos \\ Universidad Central del Ecuador, Ciudadela Universitaria, Av. América, Quito, Ecuador. \\ Autores para correspondencia: yoli_ec@yahoo.com,rodrigo.cobos537@gmail.com \\ Fecha de recepción: 23 de agosto 2016 - Fecha de aceptación: 19 de septiembre 2016
}

\begin{abstract}
Stress reflects the body's response to different demands, and it is generally accepted that good and bad experiences can cause stress. There is positive (eustress) and negative stress (distress), and both affect people. The factors causing stress range from physiological (e.g., fear of danger) too emotional (e.g., worry about money or family), and vary from person to person. The research question of this study was if the causes of stress are different between Latin American and American students at the Latin American Studies Program of the University of New Mexico (UNM) in Albuquerque, the United States. The article depicts how local and foreign graduate students perceive their stress. Findings revealed that the top four common stressors for college students are academic responsibility, time management, financial situation, and personal relationships. Six qualitative methods, such as observation, individual interviews, focus groups, collective analysis, social mapping, and visual analysis, were used to collect insight in the phenomenon of stress. The collected information was codified, organized, classified and consolidated using the Atlas.ti database, and analyzed using the triangulation technique. Results show that stress perception is significantly influenced by the cultural differences between the students.
\end{abstract}

Keywords: Eustress, distress, internal and external stressors, happiness index, graduate students, cultural differentiation.

\section{RESUMEN}

El estrés es un reflejo de la respuesta del cuerpo a diferentes exigencias, y por lo general se acepta que las buenas y las malas experiencias pueden causar estrés. Existe el estrés positivo (eustress) y negativo (distrés), y ambos afectan a las personas. Los factores que causan estrés van desde fisiológicos (p.e., el miedo al peligro) a lo emocional (p.e., la preocupación por el dinero o la familia), y varían de persona a persona. La pregunta de investigación de este estudio fue si las causas del estrés son diferentes entre los estudiantes de América Latina y de Estados Unidos, pertenecientes al Programa de Estudios América Latina de la Universidad de Nuevo México (UNM) en Albuquerque, Estados Unidos. El artículo describe cómo los estudiantes locales y extranjeros graduados perciben su estrés. Los resultados revelaron que los cuatro factores principales de estrés, comunes para los estudiantes universitarios, son: responsabilidad académica, gestión del tiempo, situación financiera y relaciones personales. Seis métodos cualitativos como la observación, entrevistas individuales, grupos focales, análisis colectivo, mapeo social, y el análisis visual, se utilizaron para recoger perspectivas del fenómeno del estrés. La información recogida fue codificada, organizada, clasificada y consolidada utilizando la base de datos Atlas.ti y analizada mediante la técnica de triangulación. Los resultados muestran que la percepción de estrés es significativamente influenciada por las diferencias culturales entre los estudiantes.

Palabras clave: Eustress, distress, factores internos y externos, índice de felicidad, estudiantes de posgrado, diferenciación cultural. 


\section{INTRODUCTION}

Stress affects people regardless of age, civil status, gender, economic status, profession, political affiliation, race and religious belief. It affects any person, such as students, teachers, managers, employees, drivers, housewives, among others (Mazo, 2015). Stress is a common disease of the modern world, unfortunately inevitably accompanied by negative reactions, such as headache, neck crick and is the cause of many health problems that include depression, anxiety, heart disease and stroke. According to D'Zurilla \& Sheedy (1991) are college students prone to stress due to their transitional nature of adjustment to the rudiments of higher education. For example, the change of a conservative secondary school environment to the highly cognitive level of learning at the university often results in stressful situations for the students. In the transition phase, students might face difficulties in following and comprehending lecturers (Aquino, 2003); they have to adjust to the standards and procedures of higher education, it is to the mode of fast-paced teaching-learning. Anything that poses a challenge to the students in their new environment, in which they receive less assistance from the lecturers and parents in comparison to the support received in high school, might result in stress, which with time can pose a threat to both mental and physical health. According to Prather (2013), keeping things in perspective, having fun with hobbies, and enjoying indulgences in moderation are secrets to stress busters.

The most common stressors in college life include: the new environment, exposure to new people, awareness of one's sexual identity and orientation, greater academic demands, financial responsibilities, and making its own decisions; in other words, standing on one's own feet and facing uncertainty. The pressure to perform well at the university; earning high grades can be a source of stress that affects them to succeed in making good impressions to parents, classmates and other persons. Failures become pressures that come from intrapersonal, interpersonal, academic and environmental stressors (Lucier, 2013). According to Chadna (2006) can stressors be classified as internal and external stressors, and college students look at these stressors when they fail or underperform, knowing that this will directly affect their parents and family's disapproval (Gordon \& Golanty, 2016). Reifman (2011) states that students consider these pressures as the primary concern for acceptance and honor, and often shortage in financial allowance from parents, guardians or banks is used as excuse for underperformance. The degree of failure in one's academic work determines one's level of approval (Ellis \& Harper, 1975). These approvals include romantic relationships, parents' love and financial support, the relationship with the lecturer, peer pressures, work bosses, among others.

Different factors affect how a student react to a stressor, and how much of an effect stressors have on their life. In the following a brief description is given of the most common internal and external stressors.

\section{The most commen internal stressors are:}

1) Lack of organizational skills: Disorganized which refers to a person's functioning without adequate order, systemization, or planning; uncoordinated; careless or undisciplined; sloppy. Its factors are procrastination, multitasking, lack of focus, too much to do, among others.

2) Changing eating/sleeping habits: A change of eating habit, whereby a change toward healthy food or diet is beneficial, while the excessive consumption of fast food at the other hand can be harmful to one's health. Types of sleep disorders include: nightmares, sleep talking, sleepwalking, insomnia, narcolepsy, snoring, sleep apnea, among others. Its main causal factors are eating disorders, sleeping disorders and sickness.

3) Financial problems: Students cannot afford to pay for their tuition, fees and other expenses by themselves. Financial stressors and other obligations can be tough to handle for freshmen's, even if parents help or if they are beneficiary of a scholarship. Its factors are lack of money and/or legal problems. 


\section{The most common external stressors are:}

1) Social stress: A good balance between studying and social relaxation is so important to prevent stress. However, students need to realize that attending classes and studying comes first and social activities second. The causal factors of social stress are conflicts in interpersonal relationships, the relation with classmates of opposite sex, trouble with family/friends, work with foreign people, etc.

2) Overload of study: Many university students believe that life at college still is like business as usual at high school. Student's at the university are more on their own, are less mothered by parents and teachers, and confronted with a larger volume of study material, being presented at a higher rate. It is important that students learn to plan, and to distribute over time tasks so that the daily workload becomes reasonable. The causal factors of stress due to overload of work are either too many or new responsibilities, increase in class work load, lower grade than expected, missed many classes, computer/technical problems, speaking in public, etc.

3) Competition: Independent from the study program, the competition between students can really get in over their head. Sometimes it is difficult to avoid, but unfortunately it can lead to an overtake of one's mental functioning. The most important factor causing stress competition is unbalanced living.

4) Time management: Failure in balanced management of one's time can be the consequence of over ambition, which happens when someone wants to do everything at the same time. Students love to have fun but they must work, and should estimate the time they need going to classes, seminars, laboratory sessions, the library for reading and studying. Some of the students make a schedule, others do not! The responsible factors are poor punctuality, performance, perfectionism, indecisiveness, and doing everything by oneself.

Stress can have a positive or a negative impact. Positive stress or eustress ${ }^{1}$ is generated when the person is about to reach a goal but still should work a little harder to achieve it. This drives a person to get it. Smith (1991) states that people can be motivated to improve themselves and reach a goal by having a challenge. Smith et al. (2016) define challenge as an emotion related to an opportunity that allows people to achieve their goals. Similarly, Hargrove et al. (2013) stated that eustress is fostered by hope and active engagement, and O'Sullivan (2011) claimed that eustress is significantly correlated with hope and life satisfaction. Eustress can physiologically facilitate the biological processes related to the physical recovery and immunity, which helps a person thrive. At the other hand, Crum et al. (2013) argued that when a person feels chronic stress, good or bad, it is negative.

Bad stress, also called distress ${ }^{2}$, is the type of stress with negative implications. In contrast, to eustress which is related to desirable events that a person wish (Selye, 1974) and enhances one's functioning, distress is related to depression and anxiety, damping a person's functioning, in general not easy to cope with. The body, however, does not make any physical distinction between eustress and distress. Kabat-Zinn (2013) claimed that both can be caused by the same factor, and that it simply depends on one's perception of stress (Le Fevre et al., 2006). Suedfeld (1997) says that a societal trauma (for example war) can generate both distress and eustress, such as coping, hardiness, and promoting a sense of community. Quick et al. (2013) used the bell curve created by Yerkes-Dodson ${ }^{3}$ to compare two strategies (behavioral-coping and emotional-coping) with variations in perceived stress level to demonstrate the optimum balance of stress between respectively increasing attention and interest (eustress) and impaired performance and strong anxiety (distress). In other words, both types of stress

1 The term was coined by endocrinologist Hans Selye, consisting of the Greek prefix eu- meaning "good", and stress, literally meaning "good stress".

2 Distress is a general term that is used in psychology to describe unpleasant feelings or emotions that impact one's level of functioning.

3 The Yerkes-Dodson law is an empirical relationship between arousal and performance, originally developed by psychologists Robert M. Yerkes and John Dillingham Dodson in 1908. The law dictates that performance increases with physiological or mental incitement, but only up to a point. Yerkes, R.M., J.D. Dodson, 1908. The relation of strength of stimulus to rapidity of habit-formation. Journal of Comparative Neurology and Psychology, 18, 459-482. 
are cumulative and depends on the adaption of the person. Moreover, resilience is related with both good and bad stress.

The study presented in this article focused on how American and Latin American graduate students perceive stress, considering the cultural differences and the stressors that affect local and foreign students, and is based on the limited number of existing articles discussing the cultural differences between U.S. and Latin America college students, and a study related to the perceived stress between American and Mexican college students (Matheny et al., 2008). Our research differentiates from previous studies by the inclusion of American, Mexican and Ecuadorian graduate students, and by focusing on the differences and similarities in the causes of stress, how these factors affect them and how they deal with them. More in particular, the article describes and discusses the results of an investigation conducted among local and foreign graduate students enrolled at the Latin American Studies Program of the University of New Mexico (UNM) in Albuquerque. The supportive hypothesis of the research question is that the causes and experience of stress are different between local American and foreign Latin American students.

\section{SYNOPTIC REVIEW OF CULTURAL DIFFERENCES BETWEEN UNITED STATES AND LATIN AMERICAN COUNTRIES}

According to Skye (2003), it is important and useful to realize and learn people's cultural differences in order to adapt better when sharing common objectives. The differences in culture can directly impact study abroad students' experiences and performance. For example, some distinct characteristics of Latin Americans are:

1) The existence of an emotional close relationship with family and friends, interpersonal relations involving physical or emotional intimacy, and keeping long lasting human relations.

2) The discussion and solving of personal issues with outside people, beyond intimate circles, takes considerable time because of the time needed to build confidence.

3) The trust in fate and sense of life's unpredictability.

4) The less attention given to punctuality; for example, in social meetings it would almost be considered rude to arrive on time as your host or hostess will likely not be ready. Arriving 30 minutes late is a general rule.

5) The enjoyment of time rather than managing time.

6) The emphasis on "doing" rather than "thinking", while Americans emphasize on "thinking" instead of "doing".

7) The ability of multitasking.

8) The existence of more physical contact and a closer interpersonal space between Latin American countrymen than between native Americans.

9) The importance of the physical touch, much more than for Americans.

10) Less direct communication among country men than exists between Americans, emphasizing more on the establishment of good human relations and the attitude to avoid hurting people's feelings.

11) Keeping a distance with people outside their intimate circle.

Other differences are the gender differential treatment of Latin Americans toward their American classmates. For example, friendship with the opposite sex is not as common as it may be between Americans; when a girl tells a boy that she wants to be friend, the relationship can be interpreted in a different way. Regarding higher education, in Latin America, university education is more professional oriented (Davies et al., 1995). The word "career" means for Latin Americans both academic major and career. In many Latin American universities is education still strongly a passive process, based on the transfer of knowledge in classrooms, whereby the professor is viewed as an "expert" and "transmitter of knowledge". Latin Americans emphasize on "memorizing" rather than "thinking" while Americans 
emphasize on "thinking". The responsibility lays with the student rather than the professor. In addition, American universities combine teaching with research, an approach recently emerging at Latin American higher education institutes. American students are more skillful in planning than their Latin American counterpart, who think that plans are general guides than anticipated outcomes. Furthermore, bureaucracy is the norm in Latin American countries, especially in the public sector.

In relation to eating habits some Americans consume more packaged food than fresh food, some of them consume daily fast food, while others follow strict a vegetarian, flexitarian or macrobiotic diet. Latin Americans eat any kind of food and typical enjoy spending meals with their family or friends. Teens can drink alcohol occasionally in Latin America which is forbidden in the United States. Latin Americans use alcohol to distress and inhibit themselves, to develop relationships and enjoy freedom; Americans do not react in the same way. Certainly, for Latin American students shortly upon arrival in the U.S. it is important to be careful about the food they eat and the consumption of drinks to avoid negative health issues.

Latin Americans enjoy making close relationships, which makes some of their American mates to feel uncomfortable. It is necessary to understand that local students view in a different way living than foreign students, which is a key factor for success in interpersonal relations. Local and foreign students can share values and a common language, but it does not mean sharing the same behaviors. In short, differences in cultural matters remain, one cannot deny. For example, Copier (2010) argues that the American and Ecuadorian culture differs in power distance, acceptance of uncertainty, and work orientation. Power distance means that Ecuadorians have high-context communication skills which explains their caring about other people's feelings, more than their own feelings. In contrast, Americans believe that they are more educated, advanced, and more direct in saying the truth and focusing on doing their job no matter if some of their actions could hurt people's feelings. For Ecuadorians, adapting the American culture is not easy given the fear of failure, and their strong dependency on parents and family. In contrast, the American culture is a low context culture. Most Latin American citizens work hard, most of their lives focusing on making money to support their family and uncertainty in their living makes that most citizens just life from day to day, while Americans spend quite some time and energy on planning activities, and in the first-place work is oriented on supporting themselves.

Many Latin American countries are characterized by virtually no middle class, while a huge distance exists between the small upper class and the large majority of lower-class citizens. Contrary, the middle class is substantial in the US, and recognized as a stabilizing societal factor, ensuring the nation's economic prosperity. It is generally expected that the introduction of technology sustains growth and sustainability of the middle class, which on its turn leads to an increasing interest in higher education. A similar evolution is to be expected in Latin American countries. A common phenomenon associated to people that want to get a higher educational degree is the desire to increase income, because people believe that happiness is related to income. Reality is often the opposite, because it is not that easy to succeed in higher education studies, to find employment corresponding to the level of his/her academic qualifications, and to acquire a job with acceptable workload and expected level of income. Individuals who pursue this ideal might at one hand be confronted with a lot of stress and at the other hand by the experience that money not necessarily make a person happier. A common fact is that the desire to climb the social ladder or strive to an increase in income is confronted with an increase in competition. Does not a similar phenomenon exist between local and foreign students in higher education institutes who compete to increase their performance and get better grades? In both cases, people because of the associated stress might be less happy than what they expected; it is the growth in happiness not necessarily covers or exceeds the effort and stresses involved in increasing one's situation.

In summary, cultural differences can be considerably, in particular between American and Latin American students, whereby the Latin American countries share many of their cultural characteristics (Kras, 2006). 


\section{METHODOLOGY}

A total of six qualitative methods were applied to collect the basic information needed to analyze how graduate Latin American and American students (master and doctoral level) at the Latin American Studies Program of UNM experience and cope with stress. The applied qualitative data collection methods consisted of observations, individual interviews, focus groups, collective analysis, social mapping, and visual analysis. A group of 16 graduate students, respectively 4 Mexican, 4 Ecuadorian and 8 American students with an age above 21 years, who experienced during their study period stress constituted the study population of the research. Although the small size of the study population limits generalization of findings, preference was given to a limited study population as to be able of applying in-depth interviews, and to probe personal opinions, perceptions and stress feelings of each participant. The collected qualitative data are: eating habits, handling of competition, financial situation, and time management, among others. Table 1 presents a summary of the applied data collection methods and the number and nationality of the participants exposed to each method.

Table 1. Overview of applied data collection methods and involved participants per method.

\begin{tabular}{lll}
\hline Method & Instrument used & Participants \\
\hline Observation & $\begin{array}{l}\text { The "Extended Case Research"4 and "Ethnographic } \\
\text { Research Methods"5 were used for the interpretation of the } \\
\text { processes and products that are linked with cultural } \\
\text { behavior. }\end{array}$ & $\begin{array}{l}\text { Eight American and four } \\
\text { Mexican graduate students. }\end{array}$ \\
\hline $\begin{array}{l}\text { Individual } \\
\text { interviews }\end{array}$ & A questionnaire was used for individual interviews. & $\begin{array}{l}\text { Two American and three } \\
\text { Ecuadorian graduate } \\
\text { students. }\end{array}$ \\
\hline $\begin{array}{l}\text { Focus group } \\
\text { interviews }\end{array}$ & A questionnaire was used for in-depth interviews. & $\begin{array}{l}\text { Three Ecuadorian graduate } \\
\text { students. }\end{array}$ \\
\hline $\begin{array}{l}\text { Collective } \\
\text { analysis }\end{array}$ & $\begin{array}{l}\text { The "College Student's Stressful Event Checklist"6 was } \\
\text { used, which includes the internal and external stressors and } \\
\text { allows to measure the amount of stress which a variation } \\
\text { using a predetermined qualitative scale. }\end{array}$ & $\begin{array}{l}\text { Three Ecuadorian graduate } \\
\text { students. }\end{array}$ \\
\hline $\begin{array}{l}\text { Social } \\
\text { mapping }\end{array}$ & $\begin{array}{l}\text { Handmade drawings designed by the participants were used } \\
\text { as aid to identify what they consider the external and } \\
\text { internal causes of their stress and the assets they believe to } \\
\text { be helpful. }\end{array}$ & $\begin{array}{l}\text { Three Ecuadorian graduate } \\
\text { students. }\end{array}$ \\
\hline $\begin{array}{l}\text { Visual } \\
\text { analysis }\end{array}$ & $\begin{array}{l}\text { A form with seven different pictures of people with } \\
\text { different attitudes and situations was given to the } \\
\text { participants, and they were asked to write what they } \\
\text { perceive in each picture the causes or factors of stress. }\end{array}$ & $\begin{array}{l}\text { Three Ecuadorian graduate } \\
\text { students. }\end{array}$ \\
\hline
\end{tabular}

As pointed out in Table 1, eight American and four Mexican graduate students were observed during a Latin American class to watch their reactions to different interactions with the professor and among them. Then individual interviews were made of two American and three Ecuadorian students using an open-ended questionnaire to explore their thoughts about stress, followed by a focus group with three Ecuadorian students using a questionnaire for in-depth interview to gather opinions, beliefs, and attitudes about what they believe was at the basis of their stress. A total of four different Ecuadorian students participated in the last two tests. The collective analysis with focus on the strategic question

4 Extended case research applies reflexive science to ethnography to extract the general form from the unique, to move from "micro" to the "macro", and to connect the present to the past in anticipation of the future, by building on preexisting theory (Burawoy, 1998).

5 Ethnographic research is the systematic study of people and cultures. It is designed to explore cultural phenomena where the researcher observes individuals and/or the society from the point of view of the subject of the study.

6 Holmes \& Rahe, 1967. 
on "How can UNM Latin American graduate students measure their stress? was applied to three Ecuadorian students. The "College Student's Stressful Event Checklist" (Holmes \& Rahe, 1967) was used as instrument to measure the amount of stress and how the participants perceive the importance of the internal and external stressors by asking five questions after they finished the checklist. The group interview technique was used to collect data for the social mapping exercise, with the participation of three Ecuadorian graduate students to know how they feel about their stress levels. Visual analysis was applied using a form with seven different pictures of people with different attitudes and situations which was given to three Ecuadorian students, and they were asked to write the stress causes or factors that they perceived in each picture to develop an understanding about how the participants perceive stress in other people, and with which of those pictures they identify themselves. The same three Ecuadorian students participated in the last four exercises to compare their answers about the factors that causes stress.

Based on the equal tendency in the information obtained via the application of different methods to different groups of students (some groups contain American and Latin American students, while other groups consisted only of Ecuadorian students) it was decided to group the data into a single pool, as basis for the discussion and the formulation of the research conclusions.

Table 2. Initial sources of internal and external stress, causal factors and used data.

\begin{tabular}{|c|c|c|c|}
\hline Categories & Sources of stress & Factors & Sources of data \\
\hline \multirow[t]{3}{*}{$\begin{array}{l}\text { Internal stressors } \\
\text { (Personal behavior } \\
\text { stressors) }\end{array}$} & Disorganized & $\begin{array}{l}\text { Procrastination } \\
\text { Multitasking } \\
\text { Lack of focus } \\
\text { Too much to do } \\
\text { Inability to make decisions }\end{array}$ & Schedules, agenda \\
\hline & $\begin{array}{l}\text { Poor eating/sleeping } \\
\text { habits }\end{array}$ & $\begin{array}{l}\text { Eating disorders } \\
\text { Sickness }\end{array}$ & Nutritional publications \\
\hline & Financial problems & $\begin{array}{l}\text { Bankruptcy/lack of money } \\
\text { Legal problems }\end{array}$ & Budget \\
\hline \multirow{4}{*}{$\begin{array}{l}\text { External stressors } \\
\text { (Environmental } \\
\text { stressors) }\end{array}$} & Social stress & $\begin{array}{l}\text { Conflicts in interpersonal } \\
\text { relationships }\end{array}$ & $\begin{array}{l}\text { Interviews, transcripts, } \\
\text { observations }\end{array}$ \\
\hline & Work/study overload & Too many/new responsibilities & Academic calendar \\
\hline & Competition & Unbalanced lives & Syllabi, research \\
\hline & Time management & $\begin{array}{l}\text { Poor punctuality / performance } \\
\text { Rushing } \\
\text { Impatience } \\
\text { Lack of energy } \\
\text { Perfectionism } \\
\text { Indecisiveness } \\
\text { Doing everything by yourself }\end{array}$ & Schedules, agenda \\
\hline
\end{tabular}

ATLAS.ti was used to process the collected data and to derive findings. It is a software tool that supports the data analysis process by helping the researcher to find what he/she is looking for, to retrieve data in different ways, and to work with data of different nature; however, ATLAS.ti does not help the researcher to decide on the overall approach to be applied for the data analysis. The software was also used to understand the rigorousness ("trustworthiness") of the research; in other words that the appropriate tools to meet the stated objective of the investigation were used (Atlas.ti, 2016).

The steps followed were:

1) The database was created in Atlas.ti.

2) The internal and external stressors were codified in the database (see Table 2).

3) The used questionnaires and forms with the respective answers of the participants were transcribed.

4) All transcripts and documents, including the literature review, the researchers' field notes and the triangulation with different subject positions were integrated in the database.

5) Related codes were assigned to transcripts and documents. 
6) Reports and queries, with different criteria based on the most common and uncommon codes used in the transcripts and other documents, were derived from the database.

The triangulation technique was applied to cross-validate data, analyze and interpret the data in the composed Atlas.ti database. Triangulation permits testing the validity of the research and to capture different dimensions. In fact, this technique enables to identify convergences and divergences in different subject positions of the participants.

\section{RESULTS}

Triangulation of the collected data permitted to derive some convergences and divergences among the participants. Whereas convergence in this context refers to different participants with different cultural background having the same inclination and attitude, the term divergence relates to that students with a common cultural background react differently to for example stress and their causal factors. For example, almost all participating postgraduate students tend to be slow or late about doing something that should be done; the American and Ecuadorian students postpone their responsibilities because they are busy doing other things, while some Mexican and Ecuadorian students postpone by lack of punctuality or by missing classes. Some Mexican and Ecuadorian students procrastinate due to lack of focus. Mexican students seem to have a hard time to concentrate because they are occupied by other activities, while the Ecuadorian students seems to be distracted because of the confrontation with multiple responsibilities, among them taking care of their family. The main reason of the procrastinated attitude of the American students is because most of them combine their studies with work. All the American and Mexican students would like to have a better quality of life, while all the Ecuadorian students are during their study period confronted with shortage of funding. Also typical is that American and Mexican students are not keen to work in group.

Typical differences in the attitude and responses of the graduates in the study can be summarized as:

- American graduate students are not affected by eating/sleeping disorders and sickness, while some of the Mexican and Ecuadorian students are. Some Ecuadorian graduates faced major illnesses primarily because of the overload of responsibilities, workload, changes in eating/sleeping habits, and/or due to relational conflicts.

- Some American, Mexican and Ecuadorian graduates are confronted with conflicts in interpersonal relations, but for different reasons. Some of the Americans have problems with classmates of opposite sex due to discussions and disagreements in class; some of the Mexicans do not like to work in group; and some of the Ecuadorians lack time to socialize because they are too much occupied by their accompanying family and/or responsibilities.

- Punctuality scores low among the graduate students: American students mostly because of combining studies with working, Mexican students due to procrastination, and Ecuadorian students due to sickness or work overload.

- American students are keen to multitasking, while this is not the case for the Mexican and Ecuadorian students.

- Most of the American students compete while most Mexican and all Ecuadorian graduates are confronted with unbalanced life due to changes in eating/sleeping habits, lack of money, work load, competition, the striving for perfectionism, and the overload of responsibilities. Whereas the striving for perfectionism by the Ecuadorians and Mexicans is for fear of failure, by the Americans this is the consequence of their competition attitude. The work overload of the Ecuadorian participants is to a certain extend explicable because they are enrolled in a doctoral program, while most the American and Mexican participants are registered in a master program, involving considerably less work.

Table 2 was prepared by the authors of this research based on a previous research (Mazo, 2015) and the literature review presented in the first section of this paper. It depicts the Internal and External stressors and the corresponding causal factors and sources. Table 3 was developed based on Table 2, in 
line with the overall objective of this study, namely definition of the causal factors of the difference in behavior toward stress of American, Mexican and Ecuadorian graduate students. Table 3 in comparison to Table 2 shows that six factors were deleted (the factors with a line crossed through) and six factors added (factors in italic). The deletion and adding of factors stemmed from the triangulation of the information provided by the participants, of which the findings are depicted in the Figures 1 and 2.

Table 3. Final sources of internal and external stress, causal factors and used data.

\begin{tabular}{|c|c|c|c|}
\hline Categories & Sources of stress & Factors & Sources of data \\
\hline \multirow{9}{*}{$\begin{array}{l}\text { Internal stressors } \\
\text { (Personal behavior } \\
\text { stressors) }\end{array}$} & Disorganized & Procrastination & Schedules, agenda \\
\hline & & Multitasking & \\
\hline & & Lack of focus & \\
\hline & & Too much to do & \\
\hline & & Inability to make decisions & \\
\hline & Poor eating/sleeping & Eating disorders & Nutritional publications \\
\hline & habits & Sickness & \\
\hline & & Sleeping disorders & \\
\hline & Financial problems & $\begin{array}{l}\text { Bankruptcy/lack of money } \\
\text { Legal problems }\end{array}$ & Budget \\
\hline \multirow{13}{*}{$\begin{array}{l}\text { External stressors } \\
\text { (Environmental } \\
\text { stressors) }\end{array}$} & Social stress & $\begin{array}{l}\text { Conflicts in interpersonal } \\
\text { relationships }\end{array}$ & $\begin{array}{l}\text { Interviews, transcripts, } \\
\text { observations }\end{array}$ \\
\hline & & Relationship to opposite sex & \\
\hline & & Trouble with family/friends & \\
\hline & & $\begin{array}{l}\text { Work with people one doesn't } \\
\text { know }\end{array}$ & \\
\hline & Work/study overload & $\begin{array}{l}\text { Too many/new responsibilities } \\
\text { Increase in class work load } \\
\text { Missed too many classes }\end{array}$ & Academic calendar \\
\hline & Competition & Unbalanced lives & Syllabi, research \\
\hline & Time management & Poor punctuality / performance & Schedules, agenda \\
\hline & & Rushing & \\
\hline & & Impatience & \\
\hline & & Lack of energy & \\
\hline & & Perfectionism & \\
\hline & & Indecisiveness & \\
\hline & & Doing everything by self & \\
\hline
\end{tabular}

Figure 1 shows the three internal stressors and the most common causes, such as:

1) Disorganized: Procrastination, multitasking, lack of focus, too much to do.

2) Poor eating/sleeping habits: Eating disorders.

3) Financial problems: Bankruptcy/lack of money, legal problems.

Figure 2 shows the four external stressors and the most common causes, such as:

1) Social stress: Conflicts in interpersonal relationships.

2) Work/study overload: Too many/new responsibilities.

3) Competition: Unbalanced lives.

4) Time management: Poor punctuality / performance, perfectionism. 


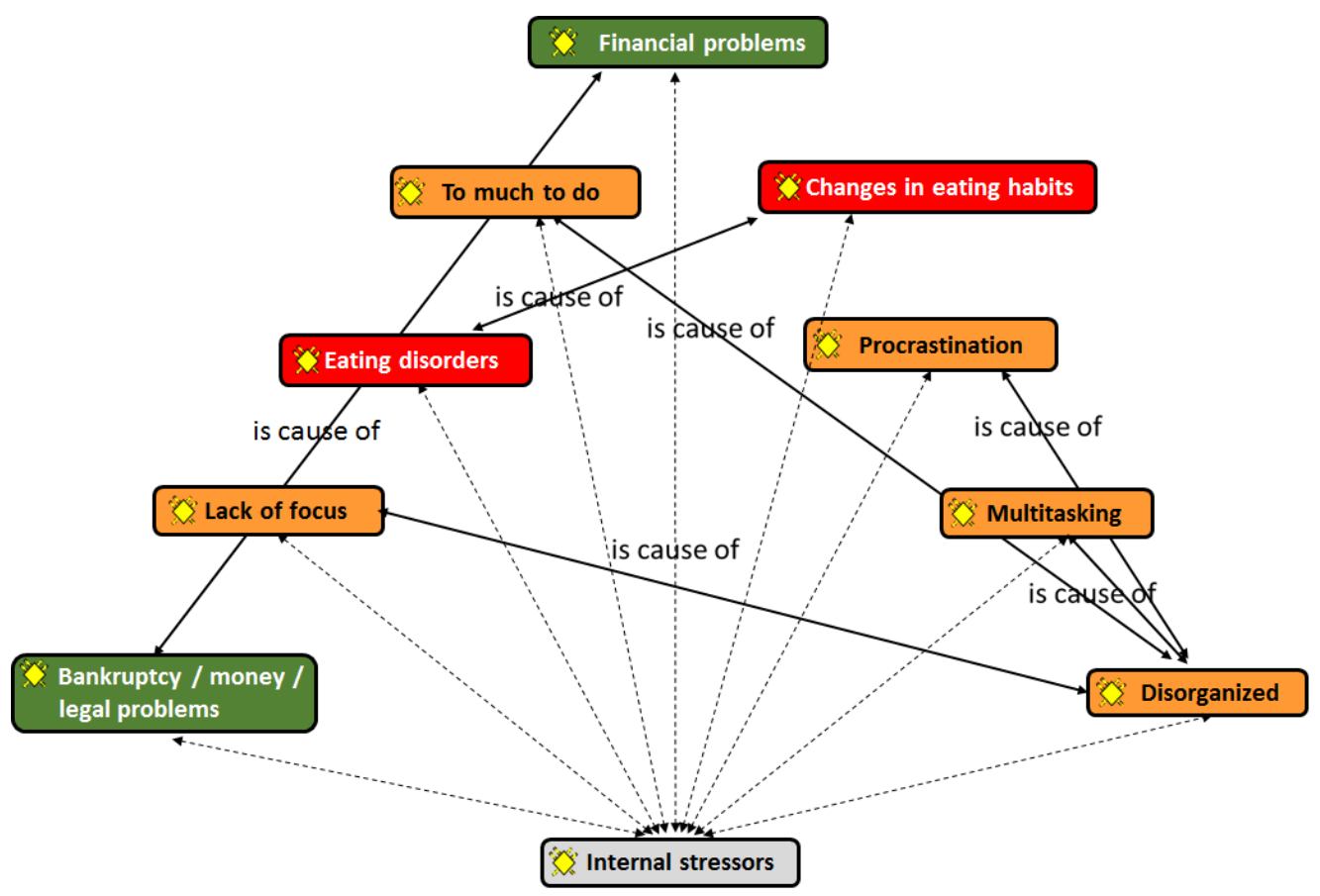

Figure 1. Relationship between causal factors and internal stressors.

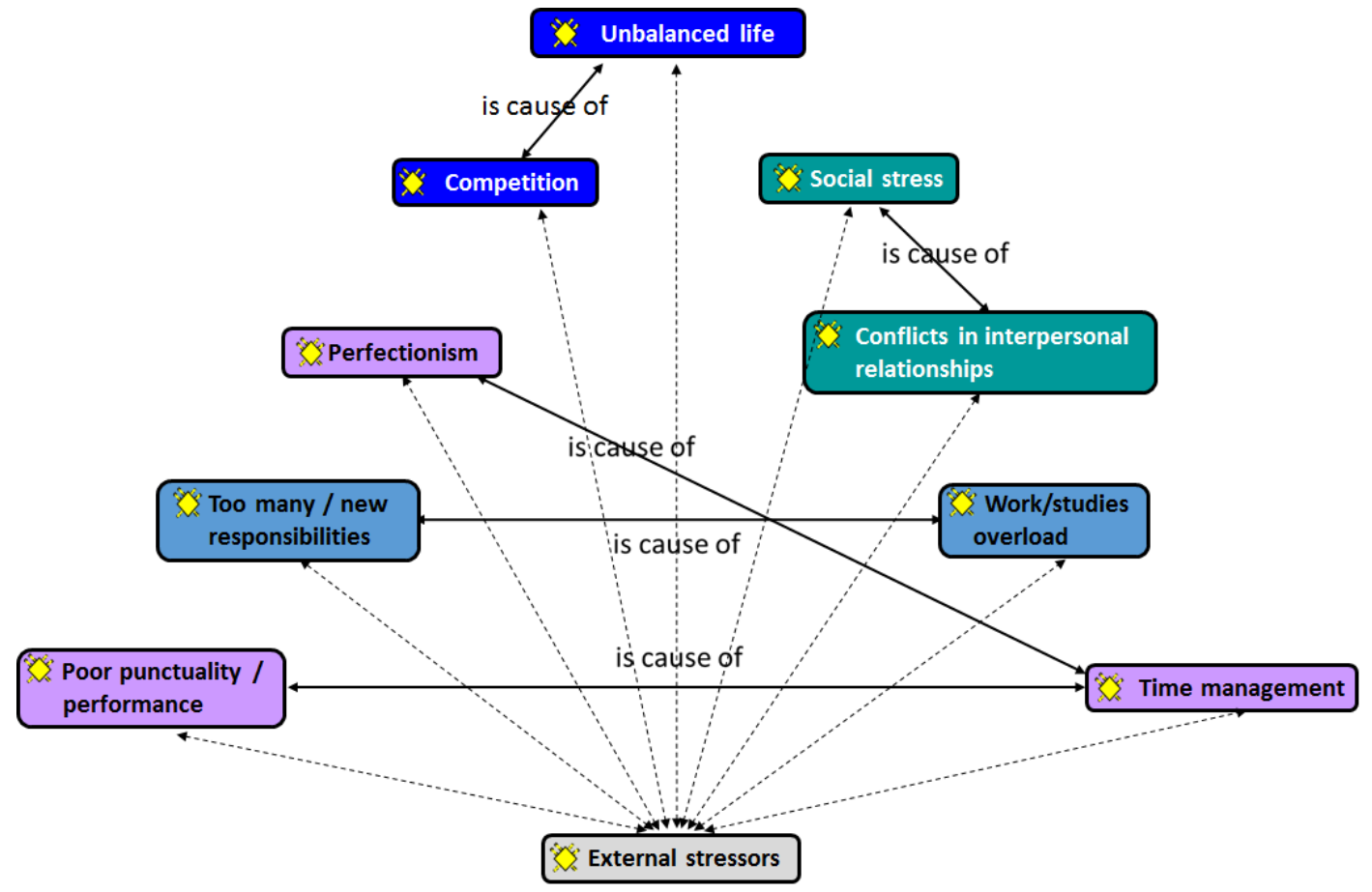

Figure 2. Relationship between causal factors and external stressors.

\section{DISCUSSION AND CONCLUSIONS}

The qualitative information collected with the six methods, ranging from observations, individual reviews, focus group discussions, collective analysis, social mapping and visual analysis, were combined with the authors' field notes, queries and reports, and processed using the Atlas.ti database technique. For the interpretation of findings use was made of related published scientific material. 
Results revealed that all graduate students are affected by internal and external stressors no matter their nationality. Although there are convergences and divergences in the causal factors producing stress, in general differences in attitude seems to be related to the cultural differences between the students. These findings are in line with what Skye (2003) argued about cultural differences that directly affect foreign students' study experiences. The pattern of internal and external stressors did not change throughout the study, but it is observed that internal stressors are often caused by external stressors. Moreover, Mazo (2015) stated that both types of stressors can affect the physical and psychological well-being of a student who needs to do something to restore that balance. In addition, it is noticed that internal stressors converge considerably more than external stressors, although among some American students more divergence than convergence is observed than among Mexican and Ecuadorian graduates. Based on the response of the participants during the personal interviews and the analysis of collected data six factors (sleeping disorders, relationship to classmates of opposite sex, trouble with family/friends, work with people one do not know, increase in class work load, missed too many classes) were added and six factors (inability to make decisions, rushing, impatience, lack of energy, indecisiveness, doing everything by oneself) eliminated. The individual interviews, focus group discussions and visual analysis revealed that the American and Ecuadorian graduates were mostly affected by external stressors, while analysis of the information obtained via observations, collective analysis and social mapping showed that the American and Ecuadorian graduates were equally affected by external-internal stressors.

Review of stress related literature demonstrates that cultural differences between people are important to explain observed differences in the factors of internal and external stressors. As Skye (2003) claims, foreign students should be aware of the cultural differences between the U.S. and Latin American countries in adapting to their new environment. For example, the participating Latin American students are emotionally much closer to their families and focus efforts in support of their loved ones, whereas Americans are more independent and first focus their efforts on themselves. This generates unbalanced conditions in the Latin American students, especially in some Ecuadorians, due to the pressures they feel to succeed and the fear of failure because their family depends on them. This is also related with other stressors, such as: changes in eating/sleeping habits, lack of money, work load, competition, and perfectionism. Another cultural difference is that American students are more inclined to think and conceptualize, while Latin Americans are more likely to learn by doing. The latter is in line with what Davies et al. (1995) stated regarding higher education in Latin America; in this region is education primarily focused on professional preparation. This phenomenon explains the difference in behavior of some Ecuadorian and Mexican students (lack of focus, procrastination, too many things to do) and some American students (multitasking, too many things to do, perfectionists, competitors). Another cultural difference is that punctuality is not a strict rule for Latin Americans. Whereas unpunctuality of Latin American citizens is a clear cultural phenomenon, unpunctuality of some American students is because they procrastinators. This coincides with the observation of Skye (2003) that Latin Americans pay considerable less attention to punctuality. The cultural difference in eating habits is also a causal factor of stress, particularly for the Latin American graduates who can eat almost any kind of food, including junk food, whereas American students tend to pursue healthier food habits. This fact reaffirms that mealtime is an important social event among Latin Americans who enjoy spending with their relatives and friends, no matter what they eat (Davies et al., 1995). Stress in the surveyed graduate students is also emerging because of poor time management, poor punctuality and procrastination. In contrast with Mazo (2015), who includes sleeping disorders as an effect, some participants of this study consider sleeplessness as a cause of other stressors such as lack of focus and procrastination.

It is important that people recognize when they are stressed, so that they can manage their stress and improve their lives. Good stress or eustress is positive in the short-term because it gives people the fuel they need to perform well. On the other hand, bad stress or distress is negative in the long-term because it drains one's energy and ability to perform well. When stressed, graduate students, or students in general, should do other activities as to decrease stress, and if the situation is running out of hand one should look for psychological aid.

Although small in scope the findings of the tentative analysis confirm the research hypothesis that differences in the causes of stress between Latin American and American graduates at the Latin America 
Studies Program of UNM are strongly controlled by cultural differences. Given the limited size of the study population, and the fact that the study was limited to students of a single program of UNM, makes that findings and conclusions cannot be generalized. However, the in-depth interview approach permitted to extract even from the small study population general perceptions, feelings and opinions. Despite this research is not generalizable, it is transferable by inviting readers to make connections between the factors that causes stress on the participants of this study and their own experience. For example, readers can identify which internal and/or external stressors graduate students have in common under certain circumstances of their lives.

\section{ACKNOWLEDGEMENTS}

The authors like to express gratitude to Professor Claudia Isaac (PhD) of the University of New Mexico, Albuquerque, for her constructive feedback and comments that improved the content of this article.

\section{REFERENCES}

Aquino, G.V., 2003. Effective teaching ( ${ }^{\text {rd }}$ ed.). Mandaluyong City, Philippines: National Book Store.

Atlas.ti, 2016. ATLAS.ti 7: User guide and reference. Available at http://atlasti.com/wpcontent/uploads/2014/05/atlasti_v7_manual_201312.pdf?q=/uploads/media/atlasti_v7_manual_2 01312.pdf, 469 pp.

Burawoy, M., 1998. The extended case method. Sociological Theory, 16(1), 4-33.

Chadna, P., 2006. Stressors-External and internal. The stress barrier-nature's way to overcoming stress. Dublin, Ireland: Blackhall Publishing.

Copier, T., 2010. Autoethnography: Differences in the American and Ecuadorian culture. StudyModeResearch, available at http://www.studymode.com/essays/Differences-In-TheAmerican-And-Ecuadorian-471588.html, 5 pp.

Crum, A.J., P. Salovey, S. Achor, 2013. Rethinking stress: the role of mindsets in determining the stress response. Journal of Personality and Social Psychology, 104(4), 716-33.

D'Zurilla, T.J., C.F. Sheedy, 1991. Relation between social problem-solving ability and subsequent level of psychological stress in college students. Journal of Personality and Social Psychology, 61(5), 841-846.

Davies, B., L. Ellison, A. Osborne, J.W. Burham, 1995. Education management for the 1990's. Upper Saddle River, NJ: Financial Times Prentice Hall.

Ellis, A., R.A. Harper, 1975. A guide to rational living. Chatsworth, CA: Wilshire Book Co.

Gordon, E., E. Golanty, 2016. Health and wellness. Burlington, MA, Jones and Bartlett Learning.

Hargrove, M., D. Nelson, C. \& Cooper, 2013. Generating eustress by challenging employees: Helping people savor their work. Organizational Dynamics, 42(1), 61-69.

Holmes, T.H., R.H. Rahe, 1967. College student's stressful event checklist: Instructions. Available at https://students.asu.edu/files/StressChecklist.pdf, 2 pp.

Kabat-Zinn, J., 2013. Full catastrophe living - How to cope with stress, pain and illness using mindfulness meditation. London, United Kingdom: Piatkus Book.

Kras, E.S., 2006. Management in two cultures: Bridging the gap between U.S. and Mexican managers. New Scotland, NY: Intercultural Press.

Le Fevre, M., G.S. Kolt, J. Matheny, 2006. Eustress, distress and their interpretation in primary and secondary occupational stress management interventions: which way first? Journal of Managerial Psychology, 21(6), 547-565. 
Lucier, K.L., 2013. How to identify the sources of stress in college. Retrieved on the $1^{\text {st }}$ of May 2016, from http://collegelife.about.com/ od/healthwellness/a/How-To-Identify-The-Sources-Of-StressIn-College.htm.

Matheny, K.B., B.E. Roque, W.L. Curlette, 2008. Perceived stress, coping resources, and life satisfaction among U.S. and Mexican college students: A cross-cultural study. Anales de Psicología. Servicio de Publicaciones de La Universidad de Murcia, 24(1), 49-57.

Mazo, G.N., 2015. Causes, effects of stress, and the coping mechanism of the Bachelor of Science in Information Technology students in a Philippine University. Journal of Education and Learning, 9(1), 71-78.

O'Sullivan, G., 2011. The relationship between hope, eustress, self-efficacy, and life satisfaction among undergraduates. Social Indicators Research, 101(1), 155-172.

Prather, C., 2013. 8 stress busters: More balance means less stress and a better body. Retrieved on the $1^{\text {st }}$ of May 2016, from http://www.bodybuilding.com/fun/8-stress-busters-more-balancemeans-less-stress-better-body.html.

Quick, J.C., T.A. Wright, J.A. Adkins, D.L. Nelson, J.D. Quick, 2013. Preventive stress management in organizations ( $2^{\text {nd }}$ ed.). Washington D.C.: American Psychological Association.

Reifman, A., 2011. Stress in college students. Retrieved on the $1^{\text {st }}$ of May 2016, from https://www.psychologytoday.com/blog/the-campus/201110/stress-in-college-students.

Selye, H., 1974. Stress without distress. Philadelphia, PA: Lippincott Williams \& Wilkins.

Skye, S., 2003. Understanding the Spanish-speaking South Americans: Bridging Hemispheres. Boston, MA: Intercultural Press, Inc.

Smith, C.A., 1991. The self, appraisal and coping. Handbook of Social and Clinical Psychology: The Health Perspective. Elmsford, NY: Pergamon Press Inc.

Smith, C.A., E.M. Tong, P.C. Ellsworth, 2016. The differentiation of positive emotional experience as viewed through the lens of appraisal theory. In: Tugade, M.M., M.N. Shiota, L.D. Kirby (Eds.), Handbook of Positive Emotions (pp. 11-27). New York, NY: Guilford Press.

Suedfeld, P., 1997. Reactions to societal trauma: Distress and/or Eustress. International Society of Political Psychology, 18(4), 849-861. 